Physical Disabilities: Education and Related Services, 2016, 35(1), 17-27. doi: 10.14434/pders.v35i1.20499

(C) Division for Physical, Health and Multiple Disabilities

\title{
PDERS
}

ISSN: 2372-451X

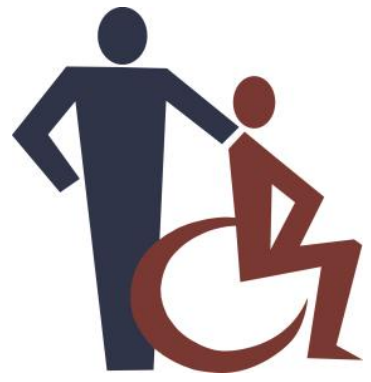

http://scholarworks.iu.edu/journals/index.php/pders/index

Article

\section{A STRATEGY FOR EMBEDDING FUNCTIONAL MOTOR AND EARLY NUMERACY SKILL INSTRUCTION INTO PHYSICAL EDUCATION ACTIVITIES}

\author{
Stacie B. Whinnery \\ University of West Florida \\ Keith W. Whinnery \\ University of West Florida

\section{Daisy Eddins} \\ Santa Rosa County School District
}

\begin{abstract}
This article addresses the challenges educators face when attempting to find a balance between both functional and academic skill instruction for students with severe, multiple disabilities including motor impairments. The authors describe a strategy that employs embedded instruction of early numeracy and functional motor skills during physical education activities in order to address both curricular foci. They present a step-by-step process for collaboratively identifying targeted skills, developing embedded activities and systematically teaching within game-based activities.
\end{abstract}

Keywords: early numeracy skills; functional motor skills; embedded instruction 


\section{Introduction}

Mrs. Tomas teaches students with severe, multiple disabilities including physical impairments in a public elementary school. Her students spend a portion of their day with her in a selfcontained special education classroom, attend adapted physical education and are included into various general education classes throughout the day for grade-aligned academic instruction. Mrs. Tomas' students receive a variety of therapy services using an integrated therapy model in which services are provided in the natural routines of the day rather than in a separate environment. Mrs. Tomas has been teaching special education for 15 years and has experienced a move from segregated to integrated environments and a shift in curriculum from a main focus on functional life skills to increased emphasis on teaching core-content. Mrs. Tomas believes it is important to address both academic and functional skills, but she is becoming increasingly overwhelmed with the challenge of finding enough time within the limited instructional day to adequately meet all of her students' needs.

\section{The Importance of Addressing both Academic and Functional Skills}

Traditionally, educational programming for students with moderate and severe disabilities has focused on the acquisition of functional skills (Knight, Browder, Agnello, \& Lee, 2010). More recently, however, there has been an emphasis on academic skill instruction with the passage of the No Child Left Behind Act (NCLB, 2002) that promoted rigorous academic standards for all students (Hunt, McDonnell, \& Crockett, 2012). The mandate for providing access to the general education curriculum (i.e., academic instruction) for students with disabilities continues with the passage of the Every Student Succeeds Act (ESSA, 2015), the most recent reauthorization of the law. Additionally, changes to the Individuals with Disabilities Education Act (IDEA, 2004) required that all students with disabilities have access to, participate in, and make progress in the general education curriculum. The emphasis on academic instruction for students with disabilities has led to a concern that functional skill instruction will be abandoned and has touched off debates in the professional literature about whether one curricular approach should take precedence over the other (Hunt et al., 2012).

Education professionals who work with students with severe disabilities understand the time challenges related to quality instruction for these individuals and may see the curricular debate as an "either/or" option (Collins, Hager \& Galloway, 2011; Hunt et al., 2012). However, advocates consider both curricular approaches important and argue that well designed educational programs for students with severe disabilities can and should include both functional skill and core content instruction (Collins et al., 2011). The challenge is to find the balance between these curricular foci and to ensure that both are taught effectively.

\section{Early Numeracy Skills}

Research has shown that students with moderate and severe disabilities often have significant deficits in early numeracy skills with the majority unable to even count to five (Kearns, TowlesReeves, Kleinert, Kleinert, \& Thomas, 2011). Recently, emphasis has been placed on identifying effective strategies to build early numeracy skills for this population because of a correlation 
between these foundational skills and math progress in later years (Jimenez \& Kemmery, 2013). For students who also have physical impairments, the issue of poor math achievement is exacerbated because of reduced instruction due to time needed for physical transitions, positioning for learning and therapies, as well as increased absences often occurring with physical disabilities (Jenks, van Lieshout, \& de Moor, 2009). However, studies demonstrate that students with moderate to severe disabilities are able to learn basic mathematics with systematic instruction, and researchers advocate for a focus on early numeracy instruction to remediate these deficits in order to support mathematics achievement (Browder et al., 2012). Educators faced with a situation of "too much to teach with too little time" may need to find innovative ways to embed early numeracy instruction into the daily schedule.

\section{Functional Motor Skills}

As with academic instruction, individuals with severe, multiple disabilities including motor impairments can learn functional motor skills with systematic instruction (Barnes \& Whinnery, 2002). Functional mobility gains can lead to improved health and increased independent functioning (Whinnery \& Whinnery, 2011), as well as the ability to gain new knowledge by interacting more directly with one's environment (van Rooijen, Verhoeven, \& Steenbergen, 2010). A critical component of functional mobility instruction is intensive motor practice (Effgen \& Chan, 2010). Students with physical disabilities may have limited practice opportunities during the school day because the majority of instructional activities use seated positions. Thus, motor skill practice often focuses too heavily on stability postures used for sitting with little instruction on transfer skills (e.g., moving from sitting-to-standing and standing-to-sitting) and mobility skills (e.g., walking) (Effgen \& Chan, 2010). Now that students with disabilities are participating regularly in academic instruction, teachers may have difficulty finding time in the day for intensive mobility skill practice.

Mrs. Tomas is facing the challenge of addressing her students' academic and functional needs within the instructional day. A recent review of her students' math performance revealed that they are experiencing difficulty with math content because of deficits in early numeracy skills (e.g., rote counting, counting with one-to-one correspondence, naming numerals) that are important for success with grade-aligned math content. To address this concern, Mrs. Tomas would like to find opportunities to provide supplemental instruction of early numeracy skills. Additionally, Mrs. Tomas is concerned that an increased emphasis on academic instruction has led to her students spending more time in stationary sitting postures without receiving adequate opportunities to practice important mobility skills like standing, walking and transferring necessary for healthy and active participation in life. Mrs. Tomas decides that she needs to reach out to her educational team members to try to find a solution.

\section{Embedded Instruction}

To address the challenge of finding time for systematic instruction of priority functional and academic skills, educational teams should consider using embedded instruction. Embedded instruction has been used to successfully teach targeted skills within existing activities and routines during the school day (Hudson, Browder, \& Wood, 2013). This strategy allows educational teams to insert teaching trials into the ongoing schedule without breaking the flow of 
the routine or activity. With embedded instruction, skills can be taught in meaningful contexts thus increasing motivation and supporting the generalization of skills to different settings (Hunt et al., 2012).

This article describes a strategy that employs embedded instruction to teach students with intellectual and physical disabilities both early numeracy and functional motor skills within physical education (P.E.) activities. The P.E. class was selected as the instructional setting because it provides a motivating, game-based context allowing students to practice targeted skills in realistic activities. Teachers and therapists use a collaborative planning process to develop activities that provide opportunities for practice of priority skills to support acquisition of gradealigned content and active participation in life activities. Specific steps and examples of the planning process are provided below.

\section{Step 1: Work as a Collaborative Team}

Students with severe, multiple disabilities are typically served by a number of educational professionals including teachers, paraprofessionals, and therapists (e.g., physical, occupational, and speech). To effectively serve the needs of this population, educational teams often use a transdisciplinary team approach that promotes sharing of discipline-specific expertise among team members and the integration of therapy into naturally occurring activities and routines (Rainforth \& York-Barr, 1997). Using this approach, team members can collaborate to plan activities that embed both early numeracy and functional motor skills during P.E. thus providing important supplemental skill instruction while optimizing instructional time. Specifically, team members work together to identify the specific skills to be targeted, plan motivating game-based activities that integrate skill practice, and develop a plan for systematic instruction of targeted skills.

Mrs. Tomas works with the physical therapist and adapted P.E. teacher to address the challenge of finding time in the day to provide supplemental instruction of early numeracy and functional motor skills. The team plans to develop P.E. activities that embed both skill areas. To accomplish this, they set aside a portion of their weekly team meetings to coordinate their efforts and to share their discipline-specific expertise. Since all team members will not be able to participate in the P.E. activities, Mrs. Tomas and the physical therapist provide cross training to other team members including the paraprofessional on early numeracy skill instruction and functional motor skill instruction including the use of adaptive equipment. Additionally, team members adjust their schedules so that the physical therapist can provide integrated therapy at least once per week during P.E. class.

\section{Step 2: Identify Target Skills}

When planning embedded activities, educational teams must identify specific skills to be targeted for instruction. Jimenez and Kemmery (2013) used embedded systematic instruction to teach early numeracy skills like measurement, counting, calendar skills, sets, and patterns to students with intellectual disabilities. Barnes and Whinnery (2002) used embedded instruction within natural contexts to teach functional walking skills to students with severe, multiple disabilities. The embedded P.E. activities presented in this article provide a context for teaching 
the following early numeracy skills: identifying numerals, naming numerals, rote counting, counting objects with one-to-one correspondence, and comparing sets. Additionally, the P.E. game-based activities provide a meaningful and motivational setting for teaching functional walking skills. Students can practice taking reciprocal steps while being provided an appropriate level of support as determined by the physical therapist (e.g., walking without support, walking with one hand held for balance, walking using an adaptive walker/gait trainer that provides support for weight bearing and balance). Figure 1 shows an example of an individual plan for Martin that highlights his targeted early numeracy and functional motor skills from a larger menu of skill options that may be embedded into the activity.

\section{Step 3: Develop an Embedded P.E. Activity}

Research supports the use of embedded instruction for teaching students with severe disabilities (Barnes \& Whinnery, 2002, Browder et al., 2012; Hudson et al., 2013). When planning embedded instruction, practitioners identify existing routines within the school day in which to incorporate supplemental instruction to teach priority skills and remediate skill deficits. Specific examples could include having students practice reading sight words posted on the bathroom wall when washing their hands, identifying shapes found in the school hallway while walking to the lunchroom, and reading a map to follow a specific path when transitioning between activities. This approach provides a viable solution for addressing the challenge of teaching both core content and functional skills within the limits of the school day.

In this example of embedded instruction, the educational team collaborates to develop P.E. activities that include early numeracy and functional mobility skill instruction. The educational team reviews the P.E. curriculum to identify opportunities to embed targeted skill instruction within motivating activities. These activities are then enhanced to include opportunities for differentiated skill practice depending upon students' individual needs. For example, a bowling game provides a meaningful context for some students to practice counting objects (e.g., counting the number of bowling pins) while others work on comparing sets (e.g., comparing the set of knocked down pins to the set of those still standing). Within the same bowling game, a few students may need to practice walking with one hand-held for balance while helping to set up the bowling pins. Others can take reciprocal steps using adaptive equipment that provides support for weight bearing and balance to get to the bowling ramp. Embedded instruction allows educational teams to provide a meaningful and realistic context for differentiated skill practice within existing routines.

Mrs. Tomas and her team develop two P.E. activities that embed early numeracy and functional motor skill instruction. In the first activity, Number Bowling, the team adds warm-up, set-up, and scoring steps to the existing P.E. bowling game to allow more opportunities for skill practice (see Table 1). In the second activity, Falling Numbers, the team creates a new P.E. activity that integrates rote counting, counting objects, naming numerals, and comparing sets as well as walking with or without assistance (see Table 2). 
Table 1. Number Bowling

\begin{tabular}{|c|c|c|}
\hline \multirow[b]{2}{*}{ Practice Opportunities } & \multicolumn{2}{|c|}{ Embedded Skills } \\
\hline & Motor & Numeracy \\
\hline \multicolumn{3}{|l|}{ Warm Up } \\
\hline Walk to bowling area & $\begin{array}{l}\text { Take reciprocal steps } \\
\text { with/without assistance }\end{array}$ & \\
\hline $\begin{array}{l}\text { Identify numerals when } \\
\text { shown array of cards }\end{array}$ & & Identify numerals \\
\hline $\begin{array}{l}\text { Name numerals on each } \\
\text { bowling pin }\end{array}$ & & Name numerals \\
\hline \multicolumn{3}{|l|}{ Set Up } \\
\hline $\begin{array}{l}\text { Count bowling pins as } \\
\text { teacher sets them up }\end{array}$ & & $\begin{array}{l}\text { Count objects with one-to-one } \\
\text { correspondence }\end{array}$ \\
\hline \multicolumn{3}{|l|}{ Bowling } \\
\hline $\begin{array}{l}\text { Walk to ramp to push } \\
\text { ball }\end{array}$ & $\begin{array}{l}\text { Take reciprocal steps } \\
\text { with/without assistance }\end{array}$ & \\
\hline \multicolumn{3}{|l|}{ Scoring } \\
\hline Walk to pins & $\begin{array}{l}\text { Take reciprocal steps } \\
\text { with/without assistance }\end{array}$ & \\
\hline $\begin{array}{l}\text { Count knocked down } \\
\text { pins }\end{array}$ & & $\begin{array}{l}\text { Count objects with one-to-one } \\
\text { correspondence }\end{array}$ \\
\hline $\begin{array}{l}\text { Compare knocked } \\
\text { down/standing pins } \\
\text { (knocked down pins are } \\
\text { placed inside hula hoop } \\
\text { to create a separate set) }\end{array}$ & & $\begin{array}{l}\text { Compare sets for less than/more } \\
\text { than/equal }\end{array}$ \\
\hline
\end{tabular}

Note. Skills and adaptive equipment are selected based on assessed student needs. Materials include cards with a written numeral on each, Velcro to attach cards to bowling pins, bowling pins, ball, bowling ramp, and hula hoop.

\section{Step 4: Develop a Plan for Systematic Instruction}

Once target skills are identified and embedded activities have been designed, the team uses systematic instruction to promote skill gains. Systematic instruction, an approach that employs principles of applied behavior analysis, has been shown to be effective for teaching academic skills (Spooner, Knight, Browder, \& Smith, 2012) and mobility skills (Barnes \& Whinnery, 2002) to students with severe disabilities. Specifically, systematic prompting (e.g., constant time delay and system of least intrusive prompts) and applications to real-life contexts were found to be effective for teaching mathematics to this population (Browder et al., 2012; Jimenez \& Kemmery, 2013). Task analysis and prompting have been shown to be effective for teaching functional mobility skills (Barnes \& Whinnery, 2002).

For the embedded P.E. activities, constant time delay (CTD) can be used to teach identifying and naming numerals. When using the CTD prompting system, teachers often use a zero-second 
Table 2. Falling Numbers

\begin{tabular}{|c|c|c|}
\hline \multirow[b]{2}{*}{ Practice Opportunities } & \multicolumn{2}{|c|}{ Embedded Skills } \\
\hline & Motor & Numeracy \\
\hline \multicolumn{3}{|l|}{ Warm Up } \\
\hline Walk to game area & $\begin{array}{l}\text { Take reciprocal steps } \\
\text { with/without assistance }\end{array}$ & \\
\hline \multicolumn{3}{|l|}{ Set Up } \\
\hline $\begin{array}{l}\text { Teacher builds block } \\
\text { tower while students } \\
\text { count to } \mathrm{x} \text {, then stops }\end{array}$ & & Rote count to $x$ \\
\hline \multicolumn{3}{|l|}{ Tower Tumble } \\
\hline $\begin{array}{l}\text { Walk to block tower to } \\
\text { knock it over }\end{array}$ & $\begin{array}{l}\text { Take reciprocal steps } \\
\text { with/without assistance }\end{array}$ & \\
\hline \multicolumn{3}{|l|}{ Scoring } \\
\hline $\begin{array}{l}\text { Walk to knocked down } \\
\text { blocks }\end{array}$ & $\begin{array}{l}\text { Take reciprocal steps } \\
\text { with/without assistance }\end{array}$ & \\
\hline $\begin{array}{l}\text { Count number of } \\
\text { knocked down blocks }\end{array}$ & & $\begin{array}{l}\text { Count objects with one-to-one } \\
\text { correspondence }\end{array}$ \\
\hline $\begin{array}{l}\text { Name numeral on each } \\
\text { knocked down block }\end{array}$ & & Name numerals \\
\hline $\begin{array}{l}\text { Compare knocked down } \\
\text { and standing blocks }\end{array}$ & & $\begin{array}{l}\text { Compare sets for less than/more } \\
\text { than/equal }\end{array}$ \\
\hline
\end{tabular}

Note. Skills and adaptive equipment are selected based on assessed student needs. Materials include 12" $\mathrm{x} 12$ " foam or cardboard blocks (with numerals written on two sides and other sides blank).

delay (i.e., provide the prompt immediately following the task direction) during initial trials to promote errorless learning (Westling, Fox, \& Carter, 2015). For example, when teaching a student to identify a numeral, the teacher presents two cards with written numerals, gives a task direction (e.g., "find 3"), immediately points to the correct card while naming the numeral (e.g., "3"), and waits for the student's response. If the student repeats the numeral, praise is given (e.g., "Great, you found the number 3"). When the student is responding consistently with a zerosecond delay, the teacher then begins using a 4-second delay. If the student does not respond or responds incorrectly with the 4-second delay, the teacher points to and names the numeral (e.g., "This is 3").

The remaining early numeracy skills (i.e., rote counting, counting objects, and comparing sets) and the functional mobility skill of walking are taught using the system of least prompts. This system uses a prompting hierarchy moving from a less to a more intrusive prompt (e.g., gesture, verbal, model, partial physical, and full physical) to elicit a correct response (Westling et al., 2015). The team selects two prompts for each student, a controlling prompt guaranteed to elicit a correct response and a less intrusive prompt. For example, when teaching a student to walk using a gait trainer to provide support for weight bearing and balance, the teacher gives a task direction (e.g., "Walk to the bowling ramp.") then waits 5 seconds. If the student does not respond within 5 seconds or responds incorrectly, the teacher provides the less intrusive verbal prompt (e.g., "Move your feet to take steps"). If the less intrusive prompt does not result in a correct response, 
the teacher provides the controlling prompt (e.g., partial physical assistance to weight shift and take a step). Praise is given anytime the student responds correctly (e.g., "Great, you are walking to the bowling ramp"). If using a system of least prompts to teach counting objects, the teacher selects the controlling prompt and a less intrusive prompt (e.g., gestural and modeling, respectively). A task direction (e.g., "Count the bowling pins.") is given and the teacher waits 5 seconds for a correct response. If the student does not respond correctly within 5 seconds, the teacher provides the less intrusive prompt (e.g., gesturing by pointing to each pin) and waits 5 seconds. If needed, the more intrusive prompt (e.g., modeling by pointing to each pin and counting aloud) would be given.

\section{Step 5: Monitor Student Progress}

Continuous, direct assessment is a recommended practice for making instructional decisions and monitoring progress for students with severe disabilities (Westling, et al., 2015). When using embedded instruction, practitioners should monitor student progress on both academic and functional skills practiced within the activity. In the P.E. example, formative assessment is used to monitor motor and early numeracy skill gains for each student. These data can be used to monitor student progress on IEPs and inform program changes.

Mrs. Tomas developed individual activity sheets for each student that identify targeted skills, prompt systems, and specific prompts to be used to teach each skill. Figure 1 shows an activity sheet for a student, Martin, for the Number Bowling activity. The activity sheet lists all possible embedded skills for each step of the activity with Martin's targeted skills highlighted. The design of the activity sheet allows team members to see the specific prompts selected for Martin based on his current performance levels as identified during baseline data collection. This information can support consistency of prompt use across team members. Additionally, the activity sheet allows team members to record Martin's performance on each trial including the level of assistance needed to perform each skill.

\section{Summary}

Given the importance of teaching both core content and functional skills, teachers are challenged to find adequate time during the instructional day to meet the varied needs of students with disabilities. Teachers of students with severe, multiple disabilities including physical impairments face greater challenges as portions of the instructional day are dedicated to tasks like physical transitions, positioning in adaptive equipment, and educational therapies. Also, these students typically require additional practice of grade-aligned academic skills beyond their academic lessons as well as opportunities to remediate deficits in foundational skills that are impeding their progress in the curriculum. Embedded instruction is a viable strategy that allows educational teams to insert instruction of priority skills into existing routines and activities. The examples provided within this article indicate how both academic and functional skills can be embedded within the same activity to provide a motivating, game-based context to encourage active engagement and support acquisition and generalization of skills. 
Student: Martin

Directions: Highlight the student's targeted skills, record the selected prompts beside the skills, and indicate the level of assistance needed to perform the highlighted skills for each session.

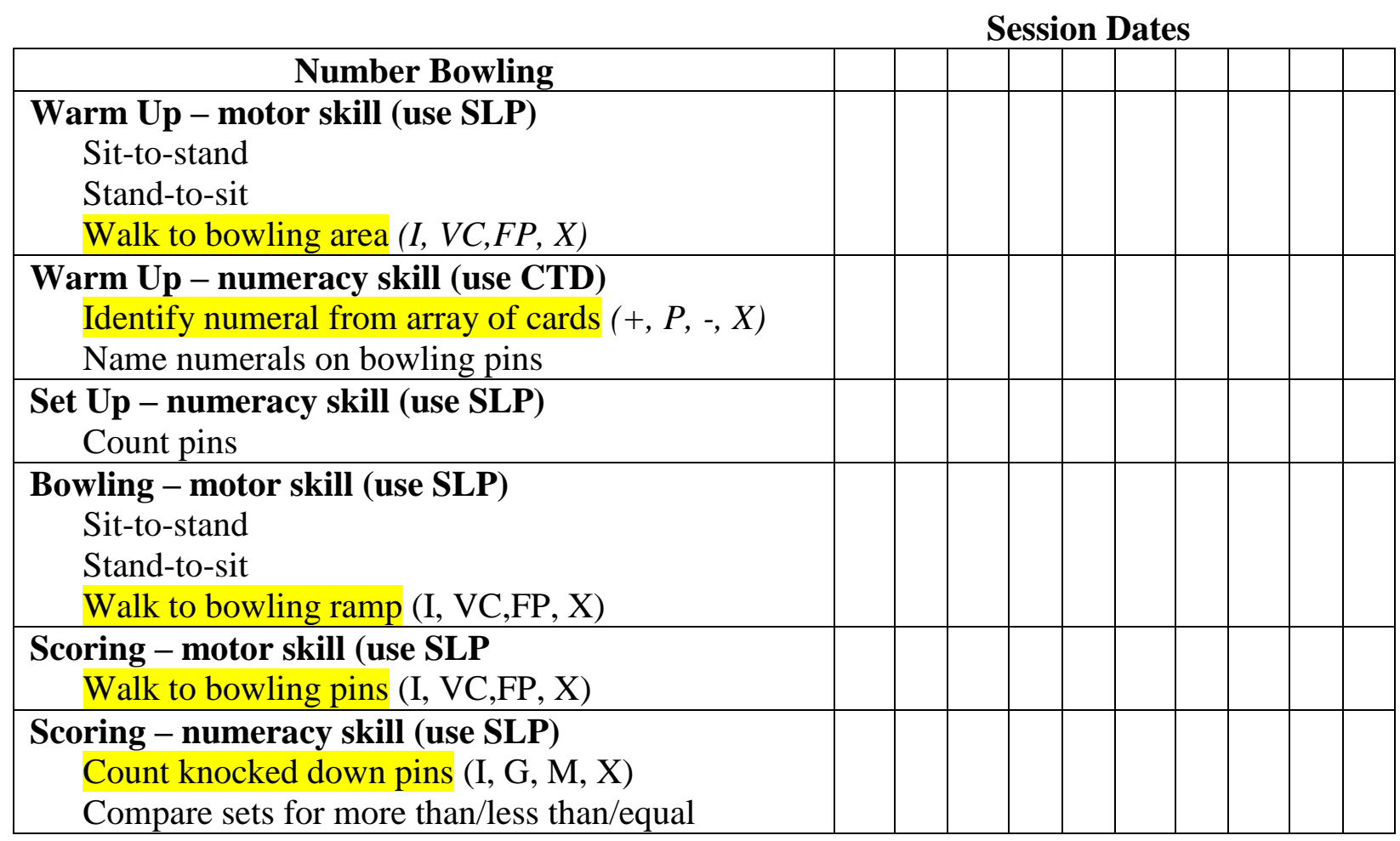

Constant Time Delay (CTD) - Used to teach identifying/naming numerals Correct response/no prompt (+), Prompted correct response (P), Incorrect response (-), No response $(\mathrm{X})$

System of Least Prompts (SLP) - Used for all remaining numeracy and motor skills

I Independent

G Gesture

VC Verbal Cue

M Model

PP Partial Physical

FP Full Physical

$\mathrm{X} \quad$ No response
Correct response with no prompt provided

Correct response after gesture is provided

Correct response after verbal statement describing what to do

Correct response after skill is modeled

Correct response after physical assistance is provided to begin task, then assistance is withdrawn

Correct response after physical assistance is continually provided No correct response with any level of prompt

Figure 1. Number Bowling Activity Sheet 


\section{References}

Barnes, S. B., \& Whinnery, K. W. (2002). Effects of functional mobility skills training for young students with physical disabilities. Exceptional Children, 68, 313-324. http://dx.doi.org/10.1177/001440290206800302

Browder, D. M., Jimenez, B. A., Spooner, F., Saunders, A., Hudson, M., \& Bethune, K. S. (2012). Early numeracy instruction for students with moderate and severe developmental disabilities. Research and Practice for Persons with Severe Disabilities, 37, 308-320. http://dx.doi.org/10.2511/027494813805327205

Collins, B. C., Hager, K. L., \& Galloway, C. C. (2011). Addition of functional content during core content instruction with students with moderate disabilities. Education and Training in Autism and Developmental Disabilities, 46, 22-39.

Effgen, S. K., \& Chan, L. (2010). Occurrence of gross motor behaviors and attainment of motor objectives in children with cerebral palsy participating in conductive education. Physiotherapy Theory and Practice, 26(1), 22-39. http://dx.doi.org/10.3109/09593980802664760

Every Student Succeeds Act of 2015, Pub. L. 114-95, S 1177 (2015).

Hudson, M. E., Browder, D. M., \& Wood, L. A. (2013). Review of experimental research on academic learning by students with moderate and severe intellectual disability in general education. Research and Practice for Persons with Severe Disabilities, 38, 17-29. http://dx.doi.org/10.2511/027494813807046926

Hunt, P., McDonnell, J., \& Crockett, M. A. (2012). Reconciling an ecological curricular framework focusing on quality of life outcomes with the development and instruction of standards-based academic goals. Research \& Practice for Persons with Severe Disabilities, 37(3), 139-152. http://dx.doi.org/10.2511/027494812804153471

Individuals with Disabilities Education Improvement Act of 2004, PL 108-466, 20 USC § 1400, H. R. 1350.

Jenks, K. M., van Lieshout, E. C. D. M., \& de Moor, J. (2009). The relationship between medical impairments and arithmetic development in children with cerebral palsy. Journal of Child Neurology, 24, 528-535. http://dx.doi.org/10.1177/0883073809335009

Jimenez, B. A., \& Kemmery, M. (2013). Building the early numeracy skills of students with moderate intellectual disability. Education and Training in Autism and Developmental Disabilities, 48, 479-490.

Kearns, J. F., Towles-Reeves, E., Kleinert, H. L., Kleinert, J. O., \& Thomas, M. K. (2011). Characteristics of and implications for students participating in alternate assessments 
based on alternate academic achievement standards. The Journal of Special Education, 45, 3-14. http://dx.doi.org/10.1177/0022466909344223

Knight, V., Browder, D., Angello, B., \& Lee, A. (2010). Academic instruction for students with severe disabilities. Focus on Exceptional Children, 42, 1-14.

No Child Left Behind Act of 2001, Pub. L. No. 107-110, 115 Stat. 1425 (2002).

Rainforth, B., \& York-Barr, J. (1997). Collaborative teams for students with severe disabilities ( $2^{\text {nd }}$ ed.). Baltimore, MD: Paul H. Brookes.

Spooner, F., Knight, W. F., Browder, D. M., \& Smith, B. R. (2012). Evidence-based practice for teaching academics to students with severe developmental disabilities. Remedial and Special Education, 33, 374-387. http://dx.doi.org/10.1177/0741932511421634

van Rooijen, M., Verhoeven, L., \& Steenbergen, B. (2010). Early numeracy in cerebral palsy: Review and future research. Developmental and Child Neurology, 53, 202-209. http://dx.doi.org/10.1111/j.1469-8749.2010.03834.x

Westling, D. L., Fox, L, \& Carter, E. W. (2015). Teaching students with severe disabilities. Boston, MA: Pearson.

Whinnery, S. B., \& Whinnery, K. W. (2011). Effects of functional mobility skills training for adults with severe multiple disabilities. Education and Training in Autism and Developmental Disabilities, 46, 436-453.

Authors' note: Address correspondence concerning this article to Stacie B. Whinnery at swhinnery@uwf.edu. 